\title{
DECLINE OF GIANT IMPACTS ON MARS BY 4.48 BILLION YEARS AGO AND AN EARLY OPPORTUNITY FOR HABITABILITY
}

Authors: D.E. Moser $^{1 *}$, G.A. Arcuri ${ }^{1}$, D.A. Reinhard ${ }^{2}$, L.F. White ${ }^{3}$, J.R. Darling ${ }^{4}$, I.R. Barker ${ }^{1}$, D.J. Larson ${ }^{2}$, A.J. Irving ${ }^{5}$, F.M. McCubbin ${ }^{6}$, K.T. Tait ${ }^{3}$, J. Roszjar ${ }^{7}$, A. Wittmann ${ }^{8}$, C. Davis ${ }^{1}$

Affiliations:

${ }^{1}$ Department of Earth Sciences, University of Western Ontario, London, Ontario N6A 5B7, Canada

${ }^{2}$ CAMECA, Madison, WI 53711, USA

${ }^{3}$ Department of Natural History, Royal Ontario Museum, 100 Queens Park, Toronto, Ontario M5S 2C6, Canada

${ }^{4}$ School of Earth and Environmental Sciences, University of Portsmouth, Portsmouth PO1 3QL, UK

${ }^{5}$ Department of Earth and Space Sciences, University of Washington, Seattle, WA 98195 USA

${ }^{6}$ NASA Johnson Space Center, Mailcode XI2, 2101 NASA Parkway, Houston, TX 77058, USA

${ }^{7}$ Department of Mineralogy and Petrography, Natural History Museum Vienna, Vienna, Austria

${ }^{8}$ Eyring Materials Center, Arizona State University, Tempe, AZ 85287-1704, USA

*Correspondence to: desmond.moser@uwo.ca

A first step to understanding the initial conditions for habitability pathways in planetary systems is to determine when heavy meteorite bombardments waned and the earliest crust remained below the known thermal and shock pressure limits on microbiota survival $\left(121^{\circ} \mathrm{C}, 78 \mathrm{GPa}\right)$. We have determined this timing on Mars by documenting the metamorphic histories of its oldest known, $4.476 \mathrm{Ga}$ to 4.430 Ga, grains of the highly resilient minerals zircon and baddeleyite in the Rabt Sbayta polymict breccia meteorites; crustal fragments of the southern highlands. Here we show using electron and atom probe microscopy that the Mars grains $(n=121)$ have all remained beneath $78 \mathrm{GPa}$ conditions, with $97 \%$ exhibiting weak to no shock metamorphic features, or thermal overprints due to shock-induced melting and magmatism. This is opposite to bombarded crust on Earth and Moon wherein $\sim \mathbf{8 0 \%}$ of grains show such features. The nearly pristine state of the Mars minerals thus establishes a lower age bracket of $4.48 \mathrm{Ga}$ for the planet-scale impact that created the hemispheric dichotomy, and obviates any later cataclysmic bombardments. Considering existing thermal habitability models, portions of early Mars crust reached habitable conditions by at least $4.2 \mathrm{Ga}$, the onset of the martian 'wet' period, as much as $\sim 500$ million years earlier than the earliest record of life on Earth. An early giant impact period on Mars, broadly coeval with Moon formation, may have heralded early abiogenesis on both planets. 
The search for evidence of life on Mars continues to be a focus of planetary research, and

46 recent work $^{1}$ has heightened interest in the age range of crust that could have hosted life.

47 Determining the earliest time window of martian habitability, however, requires measurement of

48 the age at which the earliest crust transitioned permanently to a state in which both the intense

49 shock pressures and heat (direct and indirect) caused by the early impact bombardment epoch

50 subsided below viability thresholds for Earth-like deep biosphere ${ }^{2,3}$. Ultimately this transition

51 depends on the timing and rate of delivery of impact energy to the inner solar system, a poorly

52 constrained quantity ranging from exponential decline from the time of planet accretion at 4.56

$53 \mathrm{Ga}$ and Moon formation at $\sim 4.50 \mathrm{Ga}^{4,5}$ to a later pulse at $4.0 \mathrm{Ga}$ to $3.8 \mathrm{Ga}$ due to proposed gas

54 giant migration; the hotly debated late heavy bombardment (LHB) ${ }^{6}$. Thermal habitability

55 windows for hypothermophiles range correspondingly; from transient episodes between $4.4 \mathrm{Ga}$

56 and $4.1 \mathrm{Ga}$, to a much later window at $3.8 \mathrm{Ga}^{3}$. Shock pressure waves of tens of GPa created by

57 bombardment can also frustrate life, however experiments reveal thresholds for survival as high

58 as $78 \mathrm{GPa}^{7}$ with resilience for pressure-adapted bacteria ${ }^{8}$. Here we present a test of which

59 bombardment scenario applies to early Mars by reconstructing the maximum shock pressures

60 and temperatures experienced on Mars by zircon and baddeleyite from the oldest known martian

61 crust within the Rabt Sbayta Martian polymict breccia meteorites in combination with recent

62 thermochronology 9

\section{Zirconium minerals as metamorphic indicators}

64 Zircon and baddeleyite are relatively common accessory minerals in planetary crusts and 65 are known to faithfully record large length-scale (hundreds of kilometers) and large magnitude

66 thermal and pressure perturbations that are otherwise erased in the rock record ${ }^{10}$. Micro-scale

67 effects of heat $\left(>400^{\circ} \mathrm{C}\right)$ include resorption of crystal facets, micro-zircon growth, and/or 
68 epitaxial overgrowths of metamorphic zircon ${ }^{11}$ or, in the case of baddeleyite, rounding and 69 truncation of igneous zoning and/or replacement by zircon ${ }^{12}$. At the nano-scale, atom probe 70 tomography (APT) shows that high temperature $\left(>800^{\circ} \mathrm{C}\right)$ metamorphism causes clustering of 71 trace elements such as $\mathrm{Pb}, \mathrm{Al}$ and $\mathrm{Y}^{13,14}$. Extreme heat $\left(>900^{\circ} \mathrm{C}\right)$ resulting from shock waves $>40$

$72 \mathrm{GPa}^{15}$ also produce diagnostic micro-features. In zircon these include curviplanar fractures, 73 partly lined with impact melt, partial to total conversion to granular neoblasts ${ }^{10,16}$, or, in impact 74 melt sheets and ejecta blankets, breakdown of zircon to $\mathrm{ZrO}_{2}$ and silica ${ }^{17}$.

75 The micro- and nano-scale indicators of shock pressure $\geq 40 \mathrm{GPa}$ differ for zircon and 76 baddeleyite. Zircon micro-scale features include lamellae or granules of the high-pressure 77 polymorph reidite ${ }^{18}$. Baddeleyite is more sensitive to shock pressure than most rock-forming 78 minerals, exhibiting microscopic, orthogonally-related reversion twins following shock above 5 $79 \mathrm{GPa}^{19}$, and grains at pressures above $>29 \mathrm{GPa}$ are converted to defect-rich, nanocrystalline 80 assemblages as seen in young martian meteorites ${ }^{20}$. At the nano-scale, shock metamorphism of 81 baddeleyite combined with indirect heating to $\sim 750^{\circ} \mathrm{C}$ by a kilometres-thick melt sheet caused 82 nanoclustering of trace elements $\mathrm{U}, \mathrm{Fe}$, and $\mathrm{Mn}^{21}$, whereas zircon at $>40 \mathrm{GPa}$ and $900^{\circ} \mathrm{C}$ exhibits 83 nanoclustering of $\mathrm{Pb}$ and $\mathrm{Al}$ (see below). These features can survive post-impact annealing 84 effects that otherwise erase shock effects in rock-forming minerals (quartz, plagioclase) ${ }^{10}$ as well 85 as fluvial and glacial surface transport following crater erosion ${ }^{22}$. We have compared this large 86 suite of indicators of pressure $\geq 5 \mathrm{GPa}$ and temperatures $>400^{\circ} \mathrm{C}$ to the properties of individual 87 zircon and baddeleyite grains from early Mars preserved in the meteorite North West Africa 88 (NWA) $7034^{23}$ and paired meteorites (collectively, the "Martian polymict breccia" meteorites).

89 Meteoritic crustal fragments of early Mars 
The Martian polymict breccia meteorites are recognized as a rare sample of the martian 91 regolith ${ }^{24}$, launched most likely from Mars' southern highlands ${ }^{24-26}$, that consists of clasts of 92 impact melt together with crystal and lithic fragments of Mars' oldest crust ${ }^{24,27,28}$. The 93 chronology and lithologic makeup of these paired stones have been studied by numerous groups, 94 and some common elements in their evolution have become apparent. The breccia contains 95 diverse clasts of crystalline igneous, sedimentary, and vitrophyric rocks ${ }^{24,26,29}$ that were 96 assembled and welded ${ }^{29}$ during a high energy event that produced melt clasts and impact 97 spherules with impactor component ${ }^{24}$. The age of this impact event was initially estimated at $98 \sim 1.4 \mathrm{Ga}^{25,29}$, although recent thermochronology suggests a date as young as $0.2 \mathrm{Ga}^{9}$. Launch to 99 Earth occurred at least 5 million years ago ${ }^{9,30}$. The launch event exposed the meteoroid to shock 100 pressures between 5 and $15 \mathrm{GPa}$, creating open fractures that presently cross-cut all components 101 of the meteorites. These were infilled by carbonate during residence in the Rabt Sbayta region of 102 the Saharan desert where the meteorites were recovered ${ }^{25,29,31}$.

103 The oldest lithic clasts are fine-grained noritic to monzonitic igneous rocks and a subset of 104 fine-grained sedimentary rocks ${ }^{25,29}$. These clasts are the hosts of accessory zircon and 105 baddeleyite, and we focus on these as they are the oldest known martian minerals and are 106 capable of preserving the highest fidelity record of shock metamorphism. Two populations of 107 crystalline zircon were recognized with ages of $4.476 \pm 0.001 \mathrm{Ga}$ and $4.430 \pm 0.001 \mathrm{Ga}$, 108 respectively ${ }^{28}$. Baddeleyite yielded $\mathrm{U}-\mathrm{Pb}$ ages in the range of the younger population of 109 zircon ${ }^{24,29}$. Raman spectroscopy $\left(v_{3}\left(\mathrm{SiO}_{4}\right)\right)$ and photoluminescence $\left(\mathrm{Dy}^{3+}\right)$ of crystalline zircon $(\mathrm{n}$ $110=10)$ from NWA 7906 and NWA 7475 reveal zoning in crystallinity due to varying radiation 111 damage (U concentration), but no evidence of zircon transformation to the high-pressure 112 polymorph reidite ${ }^{32}$. Here we present a systematic assessment of the thermal and shock history of 
113 a larger population of zircon and baddeleyite grains to compare with those from bombarded 114 Earth and Moon crust.

\section{Shock metamorphic reconstructions}

116 A total of nine polished surfaces from five paired stones (NWA 7034, 7475, 7906, 11220,

117 and Rabt Sbayta 003 (Figs. S1,2,3) were scanned with an automated SEM-BSE-EDS method

118 (see Methods). The population comprises 95 zircon and 52 baddeleyite grains (Table S1), with

$11940 \%$ of zircon and $53 \%$ of baddeleyite occurring within igneous clasts. Radiation damage in a U-

120 rich subset of the zircon population $[n=26$; mostly crystal clasts except where in sedimentary

121 clasts of NWA $7034^{29}$ ] obscured internal zoning, and these grains were not considered in our

122 study beyond inspecting grain outlines for signs of metamorphic forms (e.g., rounding, granular

123 neoblasts). All zircon grains in lithic clasts were found to have either typical prismatic form (Fig.

124 1) or irregular forms ranging from euhedral to conformable with boundaries with host grains

125 (Fig. S4). Zircon crystal clasts are generally anhedral, with some retaining one to two faceted 126 surfaces. Metamorphic features were noted in the rounded form of two crystal clasts (although

127 surface transport is another possibility for one grain) and a fractured igneous clast with $\sim 300 \mathrm{~nm}$

128 wide possible metamorphic overgrowths (Table S1). The internal microstructures of the zircon

129 and baddeleyite populations are dominated by primary zoning consistent with an igneous origin.

130 Internal zoning in crystal clasts is frequently planar, and truncated at margins indicating that they

131 were parts of larger igneous grains. Many crystal clasts were likely released into the fine grained

132 matrix through comminution of igneous clasts during high energy deposition of the breccia (Figs.

$133 \mathrm{~S} 4,5)$. The observations are similar for baddeleyite as grains within rock clasts exhibit euhedral

134 to subhedral habit, and concentric internal zoning (Fig. S7). Crystal clasts of baddeleyite are 
135 more subhedral to anhedral but exhibit the same internal zoning as within lithic clasts (Fig. S9) 136 and lithologies representing a younger martian crust ${ }^{33}$.

137 High resolution electron backscatter diffraction (EBSD) mapping of 69 zircon grains, 138 including $4.3 \mathrm{Ga}$ grains ${ }^{29}$, revealed two categories of lattice orientation change. Almost all grain 139 deformations are discrete $\left(1^{\circ}\right.$ to $\left.10^{\circ}\right)$ offsets across recent, open fracture sets, often conjugate, 140 that are continuous with the launch-related fractures of host minerals and matrix (Fig. 1, Figs. $141 \mathrm{~S} 4,5)$. Zircon between the fractures often exhibits low, $1^{\circ}$ to $3^{\circ}$, crystal plastic deformation (Fig. 142 S6) that could be related to launch or a pre-launch shock event that created the co-existing 143 spherules in the breccia. One zircon grain was found to exhibit clear pre-launch shock 144 deformation, manifest as a set of planar deformation bands (Fig. S11) representing a minimum 145 shock loading in the range of $10 \mathrm{GPa}$ to $20 \mathrm{GPa}$ based on Earth analogues ${ }^{10}$. These shock146 induced microstructures formed on Mars as they are clearly cross-cut by, and therefore pre-date, 147 launch-induced fracturing In summary, $98 \%$ of zircon grains exhibit a state of no to low $(<10$ $148 \mathrm{GPa}$ ) shock pressure metamorphism incurred during their time on Mars.

149 All 29 baddeleyite grains analyzed by EBSD exhibit some combination of primary and 150 shock-related twin domains. The primary igneous twinning is the same as that observed in 151 terrestrial baddeleyite [i.e. $\{100\}$ and $\{110\}$ twins $^{34}$ ] (Table S1). It is overprinted by $\mu \mathrm{m}$ to sub$152 \mu \mathrm{m}$ subgrains separated by either straight, high angle twin boundaries $\left(18^{\circ} /\{001\}\right)$ or irregular, 153 curved boundaries. In some grains, these discontinuous boundaries host domains with weak 154 diffraction. The majority of grains $(\mathrm{n}=26)$ displays three orthogonally related $\left(90^{\circ}\right)$ groupings of 155 orientations in $\{100\},\{010\}$ and $\{001\}$, as seen in the pole figures of Figs. S8, S10). In four 156 grains (NWA 7475; F6396, F14987, F3590, F3244; Table 1) these relationships are defined by a 157 small number of data $(50-120 \mathrm{~nm})$ in the EBSD map. For all orthogonally twinned grains, a 
158 single group of orientations forms $18^{\circ}$ cross shapes. The remaining two orientation groupings are

159 either tightly clustered $\left(<3^{\circ}\right)$ or linearly spread / loosely clustered $\left(<10^{\circ}\right)$, due to low magnitude

$160\left(1-5^{\circ}\right)$ crystal plastic deformation (e.g. NWA 7475, F28444 \{001\}). These crystallographic

161 features are comparable to those observed in baddeleyite exposed to shock metamorphism in the

1625 to $20 \mathrm{GPa}$ regime, as calibrated at the Sudbury impact structure (Canada) ${ }^{19}$. Two

163 metamorphosed baddeleyite crystal clasts were identified exhibiting replacement rims of zircon

164 (Figs. S12,13), likely due to heating and reaction with silica-rich melt prior to emplacement in 165 breccia (Fig. S12).

166 Atom probe tomography (APT) was carried out on two zircon grains and two baddeleyite 167 grains from Mars to test for nano-scale clustering of $\mathrm{Pb}$ and $\mathrm{Al}$ as seen in high temperature $168\left(>900^{\circ} \mathrm{C}\right)$ shock metamorphosed terrestrial zircon (Fig. S14). Three microtips of a euhedral 169 zircon grain in a lithic clast (Fig. S5,) and one microtip from a subhedral igneous zircon crystal 170 clast (Fig. S6) have mass spectra that match those of terrestrial reference zircon ${ }^{35}$ and exhibit 171 uniform distributions of the trace elements $\mathrm{Al}$ and Y (Figs. S5,6). Likewise, APT analysis of 172 euhedral baddeleyite attached to ilmenite (Fig. S7) and a baddeleyite crystal clast (Fig. S9) 173 yielded mass spectra that match reference terrestrial baddeleyite ${ }^{35}$ and exhibit homogeneous 174 trace elemental distributions of Fe and U. These nano-scale data agree with micro-scale zircon 175 and baddeleyite observations and the metamorphic state of the host minerals; all indicate 176 predominantly low-grade $\left(<10 \mathrm{GPa},<450^{\circ} \mathrm{C}\right)$ shock and thermal metamorphic conditions 177 throughout the $>4.43$ billion history of the crustal terrain that sourced the igneous clasts in the 178 breccia.

179 Comparison of the microstructure and $\mathrm{Pb}$-loss characteristics of these grains to those 180 from impacted crusts on the Earth and Moon show a marked difference (Table 1). Zircons from 
181 across the meta-igneous crust of the $\sim 100 \mathrm{~km}$ diameter central uplift of the largest known impact 182 on Earth, the Vredefort dome ${ }^{36}$, exhibit micro-features of $>20 \mathrm{GPa}$ shock metamorphism in $87 \%$

183 of grains (Table 1). Lunar zircon surveys reveal that the majority $(71 \%)$ of $>4$ Ga grains in

184 Apollo impact breccias ${ }^{16,37}$ show such features. The opposite case is found for the martian 185 polymict breccia wherein $98 \%$ of the zircons show weak to no shock deformation $>20$ GPa 186 during Mars residence. Likewise the baddeleyite grains exhibit microstructures that match those 187 in weak to moderately shocked domains of young martian shergottite, but none of the features of 188 grains near their launch-generated melt pockets ${ }^{20}$. This remarkably low-intensity shock history 189 for early Mars accessory minerals is in concert with the reported $\mathrm{U}-\mathrm{Pb}$ systematics which fail to 190 reveal impact-related $\mathrm{Pb}-\operatorname{loss}^{10}$ and instead preserve ancient, concordant (U-Pb) ages of $4.428 \pm$ $1910.025 \mathrm{Ga}^{24}$, and up to $4.476 \pm 0.001 \mathrm{Ga}^{28}$ for zircon, and as old as $4.382 \pm 0.06 \mathrm{Ga}$ for 192 baddeleyite $^{29}$ (Table S4).

\section{Early giant impact and opportunity for abiogenesis}

By pairing recent chronological constraints ${ }^{9,28}$ with our nano-and microstructural 195 measurements we can refine the history of Early Mars with regard to the timing of maximum 196 impact flux on its earliest stable crust and the time at which that crust reached habitable 197 conditions. Recent high-precision geochronology of NWA 7034 zircon grains reveals a precursor $1984.55 \mathrm{Ga}$ andesitic crust on Mars that melted to crystallize a secondary crust over a 50 million 199 year span of igneous activity between $4.476 \pm 0.001 \mathrm{Ga}$ and $4.430 \pm 0.001 \mathrm{Ga}^{28}$. It is likely that 200 the baddeleyite has a similar paragenesis, as it has an age range that is similar to zircon, is known 201 to crystallize from mafic magmas that solidify earlier in crustal differentiation sequence, and is 202 the dominant zirconium phase in igneous rocks from Mars ${ }^{38}$. The low shock levels of most of the 203 accessory minerals are consistent with the co-existence of primary, crystalline plagioclase in 
204 igneous clasts hosting zircon (e.g., Fig. 1) and the low shock state of rock-forming minerals in 205 general $^{26}$. Exsolution lamellae in pyroxene and ilmenite in crystal and lithic clasts of the host 206 rocks may indicate residence of the parent terrain near the surface of $\operatorname{Mars}^{25,26}$, and 207 thermochronology data indicate an upper crustal residence since $4.3 \mathrm{Ga}^{9}$. Taken together, the 208 zircon and baddeleyite population in Martian polymict breccia meteorites and their host rocks 209 derive from a crustal terrain that did not experience moderate to high shock pressures $(20-80$ $210 \mathrm{GPa})$, regional or local thermal $\left(>450^{\circ} \mathrm{C}\right)$ effects, or Pb-loss after $4.476 \pm 0.001 \mathrm{Ga}$, the age of 211 the oldest concordant zircon. These observations provide useful brackets on the timing of giant 212 impact and habitability on early Mars.

213 Calculations of heat thresholds for early life during bombardment relate to the energy214 release of impactors, and an impactor diameter of $500 \mathrm{~km}$ is sufficient to eliminate survivable 215 conditions for deep thermophiles on Mars and $\mathrm{Earth}^{39}$. An impactor as large as the size of one 216 Ceres $(\sim 1000 \mathrm{~km}$ diameter) is proposed to have struck early Mars to create its distinctive 217 hemispheric crustal dichotomy in thickness and topography ${ }^{40}$, and would have had profound 218 shock pressure and thermal consequences for crustal minerals at all scales. We can place the time 219 interval for the planet-shaping impactor collision at $4.51 \pm 0.04 \mathrm{Ga}$ based on the upper bracket of $2204.55 \mathrm{Ga}$ for first crust formation ${ }^{28}$, and a lower bracket based on the weak shock and thermal 221 metamorphic history of our samples of the secondary crust and its oldest concordant zircon age 222 of $4.476 \pm 0.001 \mathrm{Ga}^{28}$ (Fig. 2). This agrees with the minimum age bracket of $4.42 \pm 0.07 \mathrm{Ga}$ for 223 dichotomy formation derived from Sm-Nd geochronology ${ }^{41}$, with which, however, it was 224 impossible to distinguish the cause for the dichotomy as due to mantle-overturn or giant impact ${ }^{9}$. 225 Recent Lu-Hf chronological constraints show that mantle overturn was complete within 20 226 million years of planet formation ${ }^{28}$ and thus falsify an endogenous origin for the dichotomy due 
227 to 1-degree (i.e., whole) mantle overturn, as the latter requires $>100$ million years to actuate ${ }^{42}$. It 228 is possible that the zircon and baddeleyite crystallization events between $4.476 \pm 0.001 \mathrm{Ga}$ and $2294.430 \pm 0.001 \mathrm{Ga}^{28}$ represent the long period of crystallization following global melting of 230 primary crust by the giant impact (Fig. 2) in view of the high impactor content of the igneous 231 clasts $^{24}$.

232 This early, $4.51 \pm 0.04 \mathrm{Ga}$ age for the formation of the hemispheric dichotomy aligns 233 with the period of Moon formation ${ }^{4,5}$, and is a maximum age for habitability conditions (Fig. 2).

234 In fact, it establishes the start of the very early time period for which volatiles, including water 235 and organic compounds, could have been liberated and accumulated at the surface and in the 236 near subsurface through volcanic processes ${ }^{43,44}$ following giant impact. A global equivalent layer 237 of water in the range of 229 meters is thought to have been present at the martian surface early in 238 its history through such volcanic degassing ${ }^{45}$, which is enough to account for some of the early 239 water-related geomorphic features and may support the former presence of shallow seas. Our 240 shock pressure reconstruction for this period indicates the existence of a weakly shocked crustal 241 terrain that, in regard to pressure, was habitable from the beginning. The main threat from shock 242 pressure to micro-organisms in the early crustal terrains would have been the mechanical 243 shearing effects on cell walls ${ }^{46}$, however such effects are well-known to be highly heterogeneous 244 at the micro-scale ${ }^{15}$. Moreover, the terrain did not experience shock pressures $>15$ GPa, i.e. well 245 below the known upper limit of viability of $78 \mathrm{GPa}^{7}$.

246 It appears therefore that temperature, rather than shock pressure, was the more important 247 of the two factors limiting the onset of habitability of the early Mars crust. The two are tightly 248 linked during the bombardment period and have been modelled with respect to crustal 249 habitability volumes relative to early vs. late timing of peak impactor flux ${ }^{3}$. Our mineral 
250 evidence supports the 'classical post-accretion' model $^{3}$ of peak bombardment beginning at 4.57 $251 \mathrm{Ga}^{47}$ with monotonic decline causing local impact-effects (e.g., our few shocked grains, Table 252 S1), relict terrains unmodified by intense metamorphism, and crust viable for hyperthermophiles 253 down to $8 \mathrm{~km}$ as early as $4.4 \mathrm{Ga}$. This is in line with $\mathrm{U}-\mathrm{Pu} / \mathrm{Xe}$ gas thermochronology results for 254 whole rock samples of NWA 7034 that yield cooling as early as $4.319 \pm 0.046$ Ga below 255 temperatures of at least $\sim 450^{\circ} \mathrm{C}$ based on comparison with $\mathrm{Pb}$ behaviour in co-existing 256 phosphates ${ }^{9}$. For the Rabt Sbayta polymict breccia we place a conservative age estimate of 4.2

257 Ga for the time at which the crustal fragments cooled to the thermal habitability window of $258 \sim 160^{\circ} \mathrm{C}$ based on modeled rates of crustal thermal decay following post-accretion bombardment ${ }^{3}$

259 (Fig. 2). We note that there is no evidence that our sample of the southern highlands of Mars 260 suffered a later global, thermal or structural, modification of crust and hydrosphere by the 261 putative $4.0 \mathrm{Ga}$ to $3.8 \mathrm{Ga} \mathrm{LHB}^{2}$. For the Earth, the LHB is predicted to have been thermally 262 cataclysmic for life, melting the outer crust down to $10 \mathrm{~km}$, due to the cumulative effects of 263 impact-triggered surface melting and pressure release melting from the early mantle ${ }^{48}$ (Fig. 2). If

264 indeed such an event occurred, its effects were not pervasive on Mars. This is consistent with 265 dynamical modelling ${ }^{49}$ and isotopic evidence ${ }^{50}$ proposing either that Mars escaped an LHB, or, 266 our favoured hypothesis, that genitive planet migration occurred within the first 100 million 267 years of accretion ${ }^{51}$ such that an LHB never took place.

268 The time window for abiogenesis on Mars could have been as long as 700 million years, 269 from 4.2 to $3.5 \mathrm{Ga}$, based on evidence that the martian surface became much less hospitable by 270 approximately $3.5 \mathrm{Ga}^{52,53}$. This 700-million-year period is longer than Earth's Phanerozoic Eon, 271 and more than the amount of time between accretion and the first signs of life on Earth at $\sim 3.7$ $272 \mathrm{Ga}^{54}$. Based on terrestrial geology, Mars' crust could pre-date the oldest known inhabited surface 
273 of Earth by half a billion years (Fig. 2). Alternatively, based on recent dynamical models ${ }^{51}$, it is

274 plausible that Earth, like Mars, experienced major bombardment only in the first $\sim 100$ million

275 years, and likewise exhibited early habitable crustal platforms. Ar-Ar geochronology and

276 cosmogenic nuclide exposure histories suggest that the earliest Mars crust fragments are derived

277 from a terrain of hundreds of square kilometres which remained near the present surface ${ }^{9}$ as

278 opposed to having been deeply buried by later volcanism ${ }^{28}$. It is possible that this rock record of 279 earliest habitability remains accessible in the modern martian crust and pertinent to future 280 mission planning for sample return.

281

282 References:

283 1. Eigenbrode, J. L. et al. Organic matter preserved in 3-billion-year-old mudstones at Gale 284 crater, Mars. Science 360, 1096-1101 (2018).

285 2. Ryder, G. Mass flux in the ancient Earth-Moon system and benign implications for the 286 origin of life on Earth. J. Geophys. Res. 107, 5022 (2002).

287 3. Abramov, O. \& Mojzsis, S. J. Thermal effects of impact bombardments on Noachian 288 Mars. Earth Planet. Sci. Lett. 442, 108-120 (2016).

289 4. Touboul, M., Kleine, T., Bourdon, B., Palme, H. \& Wieler, R. Late formation and 290 prolonged differentiation of the Moon inferred from W isotopes in lunar metals. Nature $291 \quad 450,1206-1209$ (2007).

292 5. Barboni, M. et al. Early formation of the Moon 4.51 billion years ago. Sci. Adv. 3, $293 \quad$ e1602365 (2017).

294 6. Gomes, R., Levison, H. F., Tsiganis, K. \& Morbidelli, A. Origin of the cataclysmic Late 
Heavy Bombardment period of the terrestrial planets. Nature 435, 466-469 (2005).

296 7. Hazael, R., Meersman, F., Ono, F. \& Mcmillan, P. F. Pressure as a limiting factor for life. $297 \quad$ Life 6, 1-8 (2016).

298 8. Hazael, R., Fitzmaurice, B. C., Foglia, F., Appleby-Thomas, G. J. \& McMillan, P. F. Bacterial survival following shock compression in the GigaPascal range. Icarus 293, 1-7 (2017).

3019 9. Cassata, W. S. et al. Chronology of martian breccia NWA 7034 and the formation of the martian crustal dichotomy. Sci. Adv. 4, eaap8306 (2018).

10. Moser, D. E. et al. New zircon shock phenomena and their use for dating and

11. Kohn, M. J. \& Kelly, N. M. in Microstructural Geochronology: Planetary Records Down to Atom Scale (eds. Moser, D. E., Corfu, F., Darling, J. R., Reddy, S. M. \& Tait, K. T.) reconstruction of large impact structures revealed by electron nanobeam (EBSD, CL, EDS) and isotopic $\mathrm{U}-\mathrm{Pb}$ and $(\mathrm{U}-\mathrm{Th}) / \mathrm{He}$ analysis of the Vredefort dome. Can. J. Earth Sci. 48, 117-139 (2011).

312 13. Valley, J. W. et al. Hadean age for a post-magma-ocean zircon confirmed by atom-probe tomography. Nat. Geosci. 7, 219-223 (2014).

314 14. Piazolo, S. et al. Deformation-induced trace element redistribution in zircon revealed 315 using atom probe tomography. Nat. Commun. 7, 10490 (2016).

316 15. Stöffler, D., Hamann, C. \& Metzler, K. Shock metamorphism of planetary silicate rocks 
and sediments: Proposal for an updated classification system. Meteorit. Planet. Sci. 53, 5-

$318 \quad 49(2018)$.

319 16. Crow, C. A., Moser, D. E. \& McKeegan, K. D. Shock metamorphic history of $>4$ Ga $320 \quad$ Apollo 14 and 15 zircons. Meteorit. Planet. Sci. (2018).

321 17. El Goresy, A. Baddeleyite and its significance in impact glasses. J. Geophys. Res. 70, $322 \quad 3453-3456(1965)$.

323 18. Erickson, T. M. et al. Microstructural constraints on the mechanisms of the transformation 324 to reidite in naturally shocked zircon. Contrib. to Mineral. Petrol. 172, 6 (2017).

325 19. White, L. F. et al. Baddeleyite as a widespread and sensitive indicator of meteorite 326 bombardment in planetary crusts. Geology 46, 719-722 (2018).

327 20. Darling, J. R. et al. Variable microstructural response of baddeleyite to shock metamorphism in young basaltic shergottite NWA 5298 and improved U-Pb dating of Solar System events. Earth Planet. Sci. Lett. 444, 1-12 (2016).

330 21. White, L. F. et al. Atomic-scale age resolution of planetary events. Nat. Commun. 8, $331 \quad 15597(2017)$.

332 22. Thomson, O. A. et al. Preservation of detrital shocked minerals derived from the $1.85 \mathrm{Ga}$ 333 Sudbury impact structure in modern alluvium and Holocene glacial deposits. Bull. Geol. 334 Soc. Am. 126, 720-737 (2014).

335 23. Agee, C. B. et al. Unique meteorite from early Amazonian Mars: Water-rich basaltic 336 breccia Northwest Africa 7034. Science 339, 780-785 (2013).

337 24. Humayun, M. et al. Origin and age of the earliest Martian crust from meteorite NWA 338 7533. Nature 503, 513-516 (2013). 
339 25. Wittmann, A. et al. Petrography and composition of Martian regolith breccia meteorite $340 \quad$ Northwest Africa 7475. Meteorit. Planet. Sci. 50, 326-352 (2015).

341 26. Hewins, R. H. et al. Regolith breccia Northwest Africa 7533: Mineralogy and petrology 342 with implications for early Mars. Meteorit. Planet. Sci. 52, 89-124 (2017).

343 27. Bellucci, J. J. et al. A scanning ion imaging investigation into the micron-scale U-Pb 344 systematics in a complex lunar zircon. Chem. Geol. 438, 112-122 (2016).

345 28. Bouvier, L. C. et al. Evidence for extremely rapid magma ocean crystallization and crust 346 formation on Mars. Nature 558, 586-589 (2018).

347 29. McCubbin, F. M. et al. Geologic history of Martian regolith breccia Northwest Africa 348 7034: Evidence for hydrothermal activity and lithologic diversity in the Martian crust. $J$. Geophys. Res. Planets 121, 2120-2149 (2016).

30. Cartwright, J. A., Ott, U., Herrmann, S. \& Agee, C. B. Modern atmospheric signatures in 4.4 Ga Martian meteorite NWA 7034. Earth Planet. Sci. Lett. 400, 77-87 (2014).

31. Lorand, J. P. et al. Nickeliferous pyrite tracks pervasive hydrothermal alteration in Martian regolith breccia: A study in NWA 7533. Meteorit. Planet. Sci. 50, 2099-2120 (2015).

355 32. Roszjar, J., Moser, D. E., Hyde, B. C., Chanmuang, C. \& Tait, K. in Microstructural 356 Geochronology: Planetary Records Down to Atom Scale (eds. Moser, D. E., Corfu, F., 357 Darling, J. R., Reddy, S. M. \& Tait, K.) 113-135 (Wiley, 2017).

358 33. Moser, D. E. et al. Solving the Martian meteorite age conundrum using micro-baddeleyite 359 and launch-generated zircon. Nature 499, 454-457 (2013).

36034 Wingate, M. T. D. \& Compston, W. Crystal orientation effects during ion microprobe U- 
$\mathrm{Pb}$ analysis of baddeleyite. Chem. Geol. 168, 75-97 (2000).

362 35. Reinhard, D. A. et al. in Microstructural Geochronology: Planetary Records Down to Atom Scale (eds. Moser, D. E., Corfu, F., Darling, J. R., Reddy, S. M. \& Tait, K.) 315-326 (Wiley, 2017).

36. Therriault, A. M., Grieve, R. A. F. \& Reimold, W. U. Original size of the Vredefort Structure: Implications for the geological evolution of the Witwatersrand Basin. Meteorit. Planet. Sci. 32, 71-77 (1997).

37. Crow, C. A., McKeegan, K. D. \& Moser, D. E. Coordinated U-Pb geochronology, trace element, Ti-in-zircon thermometry and microstructural analysis of Apollo zircons.

38. Herd, C. D. K. et al. in Microstructural Geochronology: Planetary Records Down to Atom Scale (eds. Moser, D. E., Corfu, F., Darling, J. R., Reddy, S. M. \& Tait, K.) 137-166 (Wiley, 2017).

39. Sleep, N. H. \& Zahnle, K. Refugia from asteroid impacts on early Mars and the early Earth. J. Geophys. Res. 103, 28529-28544 (1998).

40. Wilhelms, D. E. \& Squyres, S. W. The martian hemispheric dichotomy may be due to a giant impact. Nature 309, 138-140 (1984).

41. Nyquist, L. E. et al. Rb-Sr and Sm-Nd isotopic and REE studies of igneous components in the bulk matrix domain of Martian breccia Northwest Africa 7034. Meteorit. Planet. Sci. 51, 483-498 (2016).

42. Watters, T. R., McGovern, P. J. \& Irwin III, R. P. Hemispheres Apart: The Crustal Dichotomy on Mars. Annu. Rev. Earth Planet. Sci. 35, 621-652 (2007). 
43. Steele, A. et al. A Reduced Organic Carbon Component in Martian Basalts. Science 337, 212-215 (2012).

44. Carr, M. H. \& Head, J. W. Martian surface/near-surface water inventory: Sources, sinks, and changes with time. Geophys. Res. Lett. 42, 726-732 (2015).

45. McCubbin, F. M. et al. Heterogeneous distribution of $\mathrm{H}_{2} \mathrm{O}$ in the Martian interior: Planet. Sci. 51, 2036-2060 (2016).

46. Horneck, G. et al. Microbial Rock Inhabitants Survive Hypervelocity Impacts on MarsLike Host Planets: First Phase of Lithopanspermia Experimentally Tested. Astrobiology 8,

47. Bottke, W. F. \& Andrews-Hanna, J. C. A post-accretionary lull in large impacts on early Mars. Nat. Geosci. 10, 344-348 (2017).

48. Marchi, S. et al. Widespread mixing and burial of Earth's Hadean crust by asteroid impacts. Nature 511, 578-582 (2014).

49. Brasser, R., Mojzsis, S. J., Werner, S. C., Matsumura, S. \& Ida, S. Late veneer and late accretion to the terrestrial planets. Earth Planet. Sci. Lett. 455, 85-93 (2016).

399 50. Dauphas, N. \& Pourmand, A. Hf-W-Th evidence for rapid growth of Mars and its status

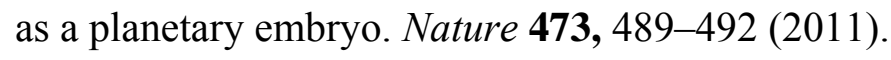

401 51. Nesvorný, D., Vokrouhlický, D., Bottke, W. F. \& Levison, H. F. Evidence for very early 402 migration of the Solar System planets from the Patroclus - Menoetius binary Jupiter Trojan. Nat. Astron. 2, 878-882 (2018).

404 52. Hurowitz, J. A. \& McLennan, S. M. A 3.5 Ga record of water-limited, acidic 
weathering conditions on Mars. Earth Planet. Sci. Lett. 260, 432-443 (2007).

406 53. Ehlmann, B. L. et al. The sustainability of habitability on terrestrial planets: Insights, questions, and needed measurements from Mars for understanding the evolution of Earthlike worlds. J. Geophys. Res. Planets 121, 1927-1961 (2016).

409 54. Rosing, M. T. ${ }^{13}$ C-Depleted Carbon Microparticles in >3700-Ma Sea-Floor Sedimentary 410 Rocks from West Greenland. Science 283, 674-676 (1999).

412 Corresponding Author: All correspondence and requests for materials should be addressed to

413 Prof. Desmond Moser, Dept. of Earth Sciences, University of Western Ontario, London,

414 Ontario, Canada N6A 5B7 ; email: desmond.moser@uwo.ca

\section{Acknowledgments:}

416 Non-Author contributions: The following curators/institutions are gratefully acknowledged for

417 providing sample material; B. Hofmann (Naturhistorisches Museum Bern, $\mathrm{CH}$ ) for loan of NWA 418 7906, John Kashuba for loan of the NWA 11220 thin sections, and Ben Hoefnagels for loan of 419 Rabt Sbayta 003. The following are gratefully acknowledged for their assistance with making or 420 running atom probe tomography specimens; Ty Prosa, Isabelle Martin, Katherine P. Rice, 421 Yimeng Chen, Dave Olson, and Daniel Lawrence.

\section{Funding:}

423 DEM acknowledges support for electron microscopy analyses, student and technical scientist 424 funding, and facility travel costs from his NSERC Discovery Grant; JRD acknowledges support 425 from Royal Society Research Grant RG160237 and a University of Portsmouth RIEF award; 

acknowledges NSERC Discovery Grant support.

Author contributions: DEM was in charge of conceptualization of the project and writing the initial draft. All authors provided support in one or more of these roles; investigation, formal analysis, resource provision, and written contributions to subsequent drafts of the manuscript. AJI was the classifier of two of the specimens used in this study and provided thin and thick sections for detailed analyses.

Competing interests: Authors declare no competing interests. We note that the CAMECA coauthors (DR and DL) are engaged in the manufacture and sale of atom probe instruments.

\section{Materials and Methods} Electron microscopy

Petrographic slabs, thick and thin sections were created from the collected samples using standard sample preparation techniques ${ }^{29}$. Sections were subjected to a final polishing step using a colloidal silica solution $(0.05 \mu \mathrm{m}, \mathrm{pH} 8.5)$ and a vibratory polisher. Electron microscopy was performed with a Hitachi SU6600 field emission scanning electron microscope (FE-SEM; Schottky emitter) located in the Zircon and Accessory Phase Laboratory at the University of Western Ontario, London, Ontario. Features of interest (e.g., zircon and baddeleyite) were initially located using backscatter electron (BSE) imaging (five segment solid-state detector) and energy dispersive spectroscopy (EDS; Oxford X-max $80 \mathrm{~mm} 2$ silicon drift detector) within Oxford INCA's Feature mapping routine, at an accelerating voltage of $15 \mathrm{kV}$; these features were subsequently overlain on BSE/EDS section montages by plotting the feature's stage coordinates using Esri's ArcGIS.

Automated SEM-BSE-EDS mapping was used to identify target grain locations and dimensions prior to characterizing micro- and nano-scale features. Many hundreds of grains, mostly in the 1 $\mu \mathrm{m}$ to $9 \mu \mathrm{m}$ size range, were detected and are mostly angular fragments in the breccia matrix. The size fraction larger than $10 \mu \mathrm{m}$ in maximum dimension $(\mathrm{n}=147)$ (Table $\mathrm{S} 1)$ was examined using electron microscopy, including Secondary Electrons (SE), Backscattered Electrons (BSE), Cathodoluminescence (CL), and Electron Backscatter Diffraction (EBSD), to determine internal zoning patterns, lattice orientation microstructure, crystallinity, and any metamorphic polymorphs (e.g., reidite) or phase-transition heritage. There is no directional fabric in the grain populations, and hence the analyzed surfaces include random intersections of larger $(>50 \mu \mathrm{m})$ grains such as those liberated by crushing ${ }^{28}$ and shown on some surfaces (e.g., Fig. S4).

Each crystalline grain ( $\mathrm{n}=121$ for martian samples) was examined using BSE and/or CL for microscopic primary features, secondary metamorphic features ${ }^{11}$, and the suite of shock metamorphic indicators described above. The largest (by length) features of each sample were 
extensively imaged using secondary electron (SE), BSE, and EDS point analysis to capture morphology and associated phases. Several of those grains were then analyzed further using other methods, including EDS mapping, cathodoluminescence (CL) and electron backscatter diffraction (EBSD). Colour CL images were collected for all but NWA 7906 with a customized Gatan ChromaCL RGB+UV detector system and Gatan Digital Micrograph software, using a 10 $\mathrm{kV}$ electron beam and 250 us pixel time. Microstructural EBSD orientation data was captured with an Oxford Nordlys detector and HKL's Channel5 software. Samples were tilted to $70^{\circ}$ within the SEM chamber and raised to a working distance of $19.0 \mathrm{~mm}$. Kikuchi patterns were generated using a $20 \mathrm{kV}, 8.0 \mathrm{nA}$ electron beam, and captured using the camera settings of 24 $\mathrm{ms} /$ frame acquisition time, $4 \times 4$ pixel binning, high gain, and frame averaging of 7 . Patterns were then indexed using a minimum of five and a maximum of seven Kikuchi bands, and a Hough transform resolution setting of 60 . Beam step-sizes during mapping were $60 \mathrm{~nm}$ to $125 \mathrm{~nm}$ but most commonly $=125 \mathrm{~nm}$. A mean angular deviation (MAD) discriminator was set to a value of 1.5 , above which analyses were assigned a zero solution to avoid indexing of poor quality EBSPs. Post-analysis noise reduction processing was not applied to any of the data sets other than removing erroneous "wild spikes". Orientation microstructure and crystallographic analysis by EBSD was used to evaluate pre- and post-launch shock-induced microstructures and search for signs of high-pressure polymorphs or their reversion products. The same instruments and procedures were used for the shock microstructural survey of zircons in petrographic thin sections across the Vredefort impact structure (Table 1) as detailed in the source M.Sc. thesis by C. Davis (https://ir.lib.uwo.ca/etd/4185/). NWA 7906 was analyzed at the Natural History Museum Vienna, Austria. CL images were obtained using a Gatan MonoCL (MonoCL4R) system attached to a JEOL JSM 6610-LV SEM. Monochromatic images are obtained by using wavelength-filtered (monochromatic) red (R)-green (G)--blue (B) setting that yield false-color (composite) RGB images, while panchromatic (gray-scale) images result from the integration of the luminescence over all emissions. Operating conditions for all SEM-Mono CL images were $15 \mathrm{kV}$ accelerating voltage, $1.2 \mathrm{nA}$ beam current, and a working distance of $\sim 11 \mathrm{~mm}$.

\section{Atom probe tomography (APT)}

APT allows the three-dimensional mapping and identification of elements and isotopes within minerals ${ }^{13}$, APT data sets were prepared by gallium focused ion beam milling at CAMECA $^{\circledR}$ Instruments Inc., Madison, Wisconsin. Standard liftout and mount techniques were used to produce the desired specimen shape with a radius of curvature $<100 \mathrm{~nm}^{55,56}$. A final low voltage $(10 \mathrm{kV})$ milling step was preformed to help minimize gallium implantation and damage. Prepared microtips were analyzed at CAMECA using a LEAP $^{\circledR} 4000 \mathrm{X} \mathrm{HR}^{\mathrm{TM}}$ atom probe equipped with a reflectron flight path and operating in laser pulsed mode. Field evaporation of each microtip was induced under ultrahigh vacuum by applying a high electric field (achieved by applying 4-12 kV) at cryogenic conditions $(\sim 50-60 \mathrm{~K})$ to the specimen apex. In laser pulse mode, ionization and evaporation of atoms on the specimen surface was promoted by an ultraviolet laser (355 $\mathrm{nm}$ wavelength) with pulse energies and frequencies that varied between $\sim 100-400 \mathrm{pJ}$ and $\sim 150-200 \mathrm{kHz}$, respectively. During acquisition, the mass-to-charge ratio of the ions is determined through time-of-flight mass spectrometry by measuring the time from field evaporation to detection and equating it to their kinetic energy. A spatial reconstruction of the specimen is achieved by projecting the ions from a position-sensitive detector back to the tip apex and considering the sequential order of evaporation. Complete detail on data acquisition and reconstruction with the local electrode atom probe are described elsewhere ${ }^{57}$. 
Data analysis and ranging of mass spectra were conducted using the Cameca IVAS ${ }^{\mathrm{TM}}$ 3.6.12 software. For each microtip dataset, corrected ionic counts of major and trace elements were calculated through the subtraction of background counts from the raw ionic counts. Background counts were measured using the local range-assisted background model in IVAS. In all scenarios, the peak locations of trace element (e.g., Y, Fe, Al, U and Pb) were identified within each microtip spectrum using the BR266 zircon standard and baddeleyite standard Phalaborwa as reference $^{35}$. For individual peaks, range bounds were set by eye from baseline to baseline to encompass the entirety of each peak ${ }^{21}$. It is noted here however, that there are no standard protocols with which to set range widths, and it is a key source of variation that is actively being explored in the field (eg., ${ }^{57,58}$ ). Details on acquisition and spatial reconstruction parameters selected for this work are given in Supplementary Data Table 3.

Data and materials availability: All data is summarized and available in the main text or the supplementary materials. Raw instrument data is available to editors and reviewers upon request.

\section{References:}

55. Larson, D. J. et al. Field-ion specimen preparation using focused ion-beam milling. Ultramicroscopy 79, 287-293 (1999).

56. Thompson, K. et al. In situ site-specific specimen preparation for atom probe tomography. Ultramicroscopy 107, 131-139 (2007).

57. Larson, D. J., Prosa, T. J., Ulfig, R. M., Geiser, B. P. \& Kelly, T. F. Local Electrode Atom Probe Tomography. (Springer, 2013).

58. Blum, T. B. et al. in Microstructural Geochronology: Planetary Records Down to Atom Scale (eds. Moser, D. E., Corfu, F., Darling, J. R., Reddy, S. M. \& Tait, K.) 237-350 (Wiley, 2017).

\section{Figure Captions:}

\section{Fig. 1. Example of early Mars crust and igneous zircon in polymict breccia meteorite NWA}

11220; (a) optical micrograph showing twinned plagioclase (grey and white banding),

540 orientation map (white box in (a)) indicating highly crystalline minerals coloured according to

541 Euler angle relative to sample urface, except for zircon grain (red), coloured according to crystal

542 axis parallel to surface. (c) highest magnification SE and CL images, and EBSD orientation map,

543 for euhedral, igneous zircon illustrating launch-related $\left[<15 \mathrm{GPa}^{25}\right]$ open fractures (white arrow). 
544 Such grains testify to the absence of major shock metamorphic effects on the source crust

545 domain since $\geq 4.43$ billion years ago.

Fig. 2. Timeline of early Mars bombardment history and habitability compared to Earth.

549 Timing of major events in the early histories of Mars and Earth showing the classical post-

550 accretion bombardment flux curve ${ }^{3}$ (red dashes), and an early period of planet-scale impact

551 effects such as formed the hemispheric dichotomy; both dictated by the existence of $\leq 4.476$

$552 \pm 0.001 \mathrm{Ga}$ grains of zircon and baddeleyite grains and host crust, unaltered by shock

553 metamorphism $>20 \mathrm{GPa}$ on Mars. Note that the Mars giant impact period overlaps current age

554 estimates for Moon formation. Early Mars crust was below shock pressure habitability after this

555 time. Thermal habitability of early Mars crust was possible at $4.4 \mathrm{Ga}^{3}$, and based on the oldest U-

$556 \mathrm{Pu} / \mathrm{Xe}$ cooling date of $4.32 \mathrm{Ga}$ for our samples ${ }^{9}$ we estimate that the source crustal terrane was

557 habitable by $4.2 \mathrm{Ga}$, a time of accelerated volatile release following dichotomy formation. Our

558 samples of Mars crust did not experience later, pervasive cataclysm at $\sim 3.9 \mathrm{Ga}$ during the

559 putative late heavy bombardment $(\mathrm{LHB})^{6}$. Habitable crust on Mars predates Earth's oldest

560 known biosignatures ${ }^{54}$ by as much as $\sim 500$ million years. The absence of shock metamorphic

561 features in Hadean Earth zircon ${ }^{13}$ and recent dynamical modelling ${ }^{51}$ allow that Earth also had

562 opportunity for early abiogenesis. Inset: NASA-MOLA false-color topographic model of the

563 Mars surface showing the hemispheric dichotomy and southern highlands (orange), a likely

564 source for the Martian polymict breccia meteorites ${ }^{24-26}$. 
Table 1. Results of in-situ shock microstructural analyses of zirconium minerals in polished sections of bombarded crust from across the central uplift of the Vredefort impact structure compared to early Mars samples. Earth values similar to Moon results (see text) $\left({ }^{*}\right)$

569 Shock metamorphism is characterized by the occurrence of any of the following features; planar

570 or curviplanar features, impact-melt glass inclusions, crystal plastic deformation, high pressure

571 polymorphs or reversion products thereof, granularization or neobastic growth, and nano-scale

572 clustering of trace elements.

\begin{tabular}{|c|c|c|c|c|c|c|}
\hline $\begin{array}{c}\text { Vredefort } \\
\text { (Earth) } \\
\text { Samples }\end{array}$ & $\begin{array}{c}\text { Distance } \\
\text { from } \\
\text { center of } \\
\text { impact }\end{array}$ & \multicolumn{2}{|c|}{ Coordinates (UTM) } & $\begin{array}{c}\text { Total } \\
\text { grains }\end{array}$ & $\begin{array}{c}\text { \# shock } \\
\text { metamor- } \\
\text { phosed* }\end{array}$ & $\begin{array}{c}\text { \% shock } \\
\text { metamor- } \\
\text { phosed* }\end{array}$ \\
\hline V15-39 & $\sim 5 \mathrm{~km}$ & $543699 \mathrm{~m} \mathrm{E}$ & $7014140 \mathrm{~m} \mathrm{~S}$ & 45 & 42 & 94 \\
\hline V15-16 & $\sim 8.6 \mathrm{~km}$ & $540091 \mathrm{~m} \mathrm{E}$ & $7010527 \mathrm{~m} \mathrm{~S}$ & 48 & 48 & 100 \\
\hline V49-1 & $\sim 8.9 \mathrm{~km}$ & $542531 \mathrm{~m} \mathrm{E}$ & $7015741 \mathrm{~m} \mathrm{~S}$ & 41 & 37 & 90 \\
\hline V15-46 & $\sim 17.1 \mathrm{~km}$ & $539943 \mathrm{~m} \mathrm{E}$ & $7025719 \mathrm{~m} \mathrm{~S}$ & 48 & 41 & 85 \\
\hline V-62 & $\sim 22.8 \mathrm{~km}$ & $534627 \mathrm{~m} \mathrm{E}$ & $7029025 \mathrm{~m} \mathrm{~S}$ & 33 & 32 & 97 \\
\hline V15-55 & $\sim 24.5 \mathrm{~km}$ & $563809 \mathrm{~m} \mathrm{E}$ & $7030330 \mathrm{~m} \mathrm{~S}$ & 36 & 18 & 50 \\
\hline Total & - & - & - & $\mathbf{2 5 1}$ & $\mathbf{2 1 8}$ & $\mathbf{8 7 \%}$ \\
\hline $\begin{array}{l}\text { Mars samples; } \\
\text { NWA 7034, 7475, }\end{array}$ & & & & & \\
7906, 11220, Rabt \\
Sbayta 003
\end{tabular}




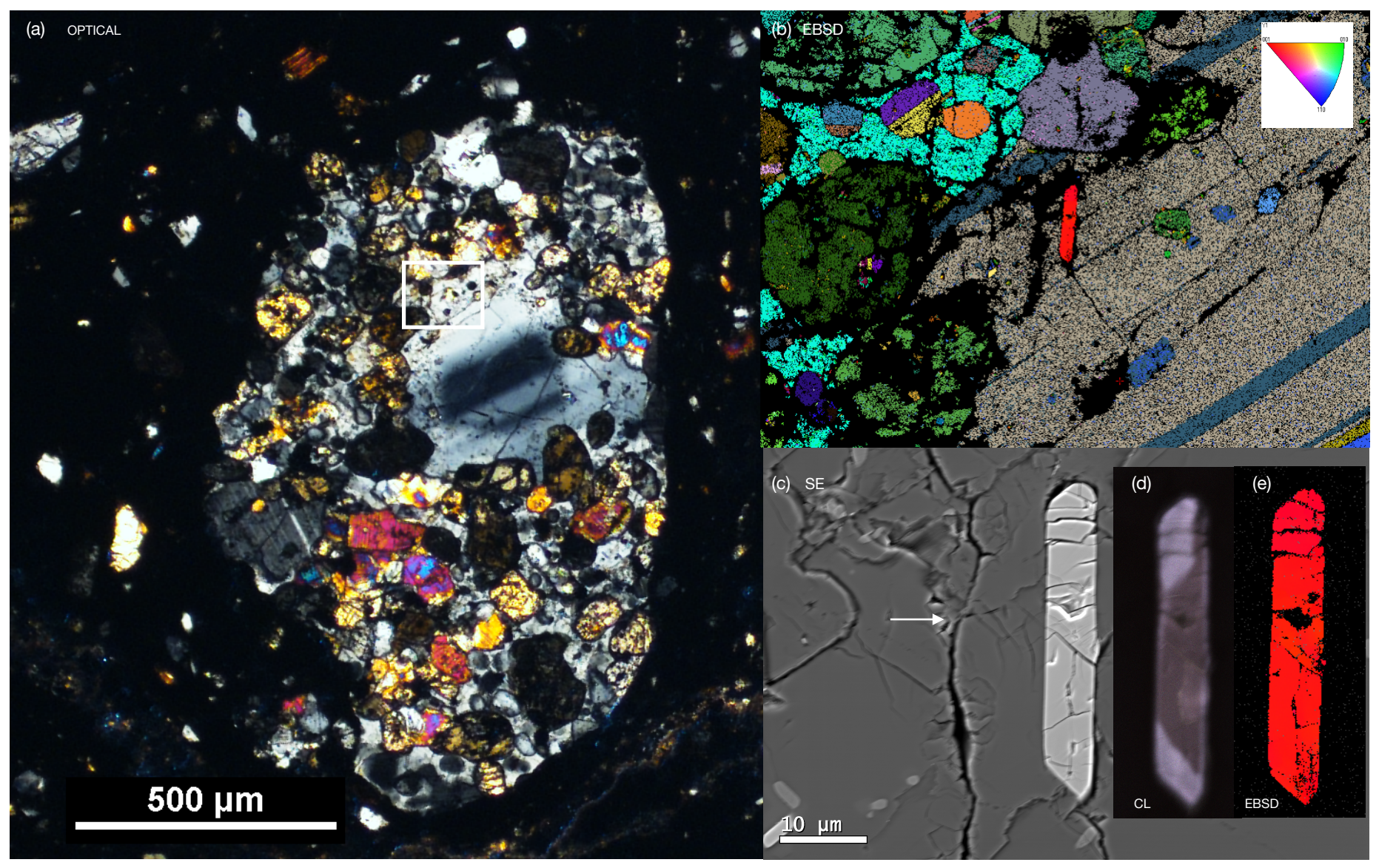

Figure 1. Moser et al. ; NGS-2018-09-02050A Mar 27, 2019 


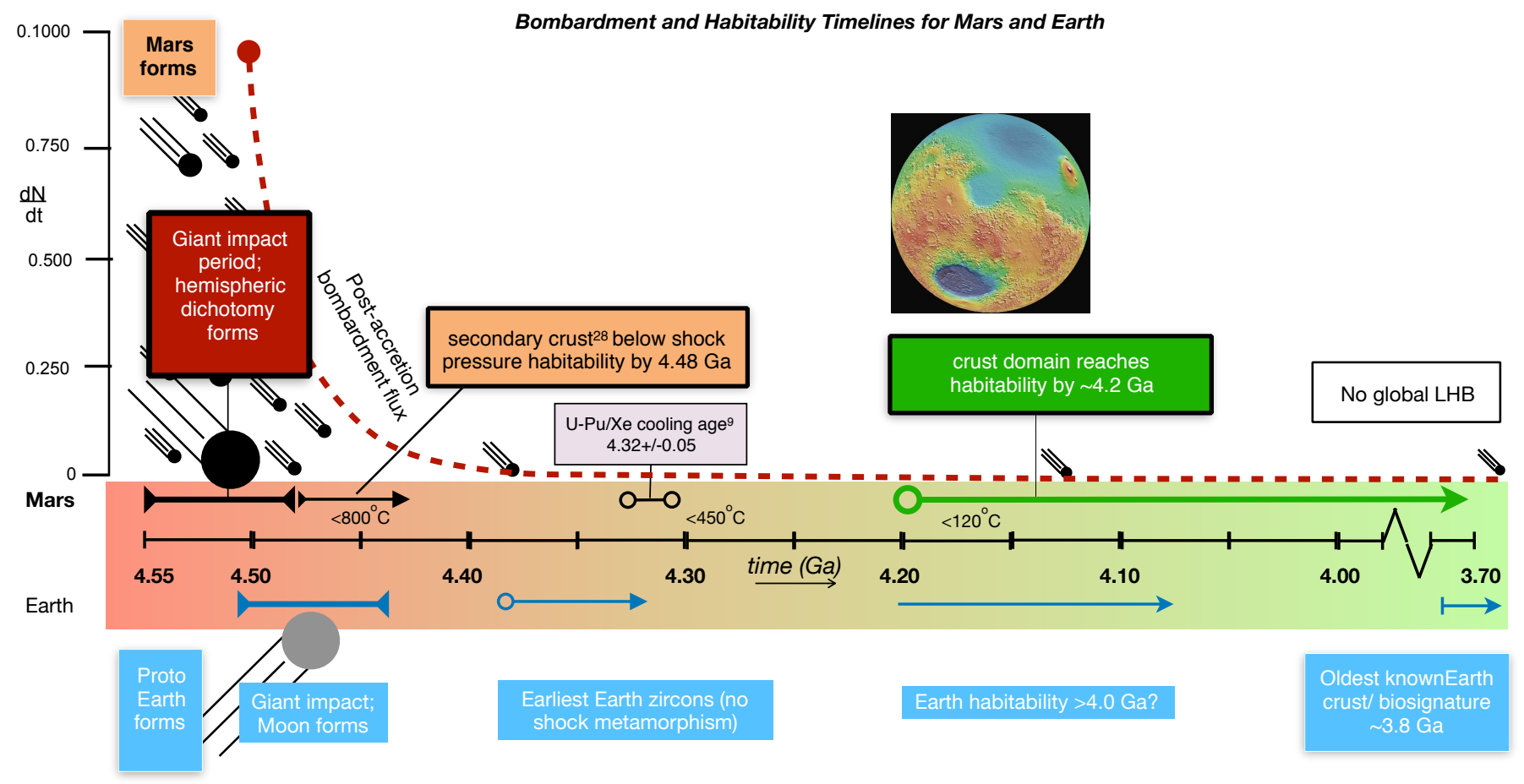

Figure 2. Moser et al. ; NGS-2018-09-02050A Mar 27, 2019 